ORIGINAL ARTICLE

\title{
Studying "exposure" to firearms: household ownership $v$ access
}

\author{
R M Ikeda, L L Dahlberg, M-j Kresnow, J J Sacks, J A Mercy
}

Injury Prevention 2003;9:53-57

See end of article for authors' affiliations

\section{Correspondence to:} Dr Robin M Ikeda, Division of Violence Prevention, 4770 Buford Highway, MS K-60, Atlanta, GA 30341 USA; rmiO@cdc.gov

\begin{abstract}
Background: Firearm ownership has often been used to measure access to weapons. However, persons who own a firearm may not have access to it and conversely, persons who do not own a firearm may be able to access one quickly.

Objectives: To examine whether using firearm ownership is a reasonable proxy for access by describing the demographic characteristics associated with ownership and access.

Methods: Data are from the 1994 Injury Control and Risk Survey, a national, random digit dial survey. Information about household firearm ownership and ready access to a loaded firearm were collected and weighted to provide national estimates. Adjusted odds ratios for three separate models were calculated using logistic regression.

Results: A total of $1353(27.9 \%)$ respondents reported both having a firearm in the household and ready access to one. An additional 313 respondents $(8.1 \%)$ reported having a firearm, but were not able to access these weapons. Another 421 respondents $(7.2 \%)$ did not have a firearm in or around their home, yet reported being able to retrieve and fire one within 10 minutes. Based on the logistic regression findings, the demographic characteristics of this latter group are quite different from those who report ownership. Those who do not have a firearm, but report ready access to one, are more likely to be ethnic minorities, single, and living in attached homes.

Conclusions: Asking only about the presence of a firearm in a household may miss some respondents with ready access to a loaded firearm. More importantly, those who do not own a firearm, but report ready access to one, appear to be qualitatively different from those who report ownership. Caution should be exercised when using measures of ownership as a proxy for access.
\end{abstract}

invol he majority of suicides and homicides in the United States involve a firearm, as do a substantial number of non-fatal injuries. ${ }^{1}$ Many interventions and policies designed to prevent these injuries focus on restricting access to firearms, either generally in a population, or among specific high risk groups, such as children and suicidal persons. ${ }^{2-4}$ However, "access" is a poorly defined concept, which limits our ability to evaluate firearm related prevention efforts.

Access to firearms can be organized along a continuum, ranging from those immediately available for use (for example, loaded and unlocked in one's own home) to those that require additional steps before being ready to use (for example, unloaded and locked in a location away from one's home, such as a firing range). Access to loaded firearms that are readily available within minutes is of particular interest, given their potential role in impulsive suicidal behavior or rapidly escalating violent interpersonal events.

Firearm ownership has often been used to measure access to firearms. However, it is generally recognized that ownership and access may represent related, yet separate, constructs. ${ }^{5}$ Persons who do not own a firearm or keep one in their home may still have access to a firearm. There are also likely to be people who own a firearm, but cannot access it quickly. Despite this conceptual distinction between firearm ownership and access, previous studies nonetheless, have used ownership as an indicator of access. ${ }^{6-11}$ The validity of using firearm ownership as a proxy for access has not been specifically studied.

To address this question, we examined demographic differences between ownership and access and identified subgroups for which ownership is not a good indicator for access.

\section{METHODS}

Data for this analysis are from the 1994 Injury Control and Risk Survey (ICARIS). This survey assessed risk factors for both unintentional and intentional injury and was based on a single stage, random digit dialing residential telephone sample of English or Spanish speaking adult respondents (aged 18 years and older) in all 50 states and the District of Columbia. The study protocol was approved by the Centers for Disease Control and Prevention Institutional Review Board.

Following receipt of informed consent, screening questions were asked about the number of adult men and women in the household. A specified procedure was used to ensure approximately equal numbers of male and female respondents. For households with more than one eligible individual, the person with the most recent birthday was interviewed. To provide adequate minority representation, all telephone exchanges were stratified by whether they had $\geqslant 10 \%$ of households occupied by minorities. Exchanges with $\geqslant 10 \%$ of households occupied by minorities were sampled at a higher rate than the others. The final sample consisted of 5238 completed interviews (response rate $=59.3 \%$ )*

In addition to demographic information about the respondent and the household, participants were asked, "Are there any loaded or unloaded firearms in your home or the car, van, or truck you usually drive? This includes firearms stored in the basement, garage, or any attached buildings". Ready access to a loaded firearm was assessed by respondents' answer to the following question, "If you were at home, could you get and be ready to fire a loaded firearm in less than 10 minutes? The weapon could be yours or someone else's and it could be located in your home or car or someone else's home or car".

* Response rate: 5238 completed interviews 15238 completed interviews +3128 eligible refusals +474 incomplete interviews) $=$ $59.3 \%$ 
Table 1 Distribution of respondent demographic characteristics within the different ownership/access categories; results are weighted \% (95\% confidence interval)

\begin{tabular}{|c|c|c|c|c|}
\hline Characteristics & $\begin{array}{l}\text { Ownership/access } \\
\text { Yes/no }(n=313)\end{array}$ & $\begin{array}{l}\text { Ownership/access } \\
\text { Yes/yes }(n=1353)\end{array}$ & $\begin{array}{l}\text { Ownership/access } \\
\text { No/yes }(n=421)\end{array}$ & $\begin{array}{l}\text { Ownership/access } \\
\text { No/no }(n=2969)\end{array}$ \\
\hline \multicolumn{5}{|l|}{ Sex } \\
\hline Male & 28.1 (22.7 to 33.5 ) & 66.5 (63.3 to 69.7) & $57.0(51.2$ to 62.8$)$ & 40.4 (38.2 to 42.7$)$ \\
\hline Female & 71.9 (66.5 to 77.3$)$ & 33.5 (30.3 to 36.7$)$ & 43.0 (37.2 to 48.8 ) & 59.6 (57.3 to 61.8$)$ \\
\hline \multicolumn{5}{|l|}{ Age group (years) } \\
\hline $18-34$ & 27.8 (21.9 to 33.6$)$ & 36.8 (33.6 to 40.0 ) & 49.4 (43.6 to 55.3 ) & $36.0(33.8$ to 38.2$)$ \\
\hline $35-54$ & 43.2 (36.6 to 49.7$)$ & 39.5 (36.3 to 42.7 ) & 30.1 (24.9 to 35.3 ) & 36.4 (34.1 to 38.6$)$ \\
\hline $55+$ & 29.1 (23.1 to 35.1$)$ & 23.7 (21.0 to 26.5$)$ & 20.5 (15.9 to 25.1$)$ & 27.7 (25.5 to 29.8 ) \\
\hline \multicolumn{5}{|l|}{ Race/ethnicity } \\
\hline White, non-Hispanic & 87.7 (83.9 to 91.5 ) & 87.6 (85.4 to 89.7$)$ & 65.8 (60.5 to 71.1$)$ & 72.6 (70.7 to 74.4$)$ \\
\hline Black, non-Hispanic & $5.6(2.8$ to 8.3$)$ & 6.1 (4.5 to 7.6 ) & $17.4(13.3$ to 21.5$)$ & 13.0 (11.6 to 14.5$)$ \\
\hline Other, non-Hispanic & $2.1(0.3$ to 3.8$)$ & $3.0(1.8$ to 4.2$)$ & 3.7 (1.6 to 5.8$)$ & 5.1 (4.1 to 6.0$)$ \\
\hline Hispanic & $4.7(2.5$ to 6.8$)$ & $3.4(2.3$ to 4.4$)$ & $13.1(9.4$ to 16.8 ) & $9.4(8.2$ to 10.5$)$ \\
\hline \multicolumn{5}{|l|}{ Marital status } \\
\hline Married & 73.7 (67.8 to 79.5$)$ & 70.1 (67.1 to 73.1$)$ & 51.2 (45.4 to 57.0 ) & $55.3(53.0$ to 57.6$)$ \\
\hline Not married & 26.3 (20.5 to 32.2$)$ & 29.9 (26.9 to 32.9$)$ & 48.8 (43.0 to 54.6 ) & 44.7 (42.4 to 47.0$)$ \\
\hline \multicolumn{5}{|l|}{ Education } \\
\hline$\leqslant$ High school & 45.2 (38.5 to 51.8 ) & 44.1 (40.8 to 47.4$)$ & 51.4 (45.6 to 57.2$)$ & 43.7 (41.3 to 46.0$)$ \\
\hline$>$ High school, $\leqslant$ college & 46.5 (39.9 to 53.1$)$ & $47.2(43.9$ to 50.5$)$ & 39.5 (33.9 to 45.1$)$ & $43.2(40.9$ to 45.4$)$ \\
\hline Postgraduate & $8.4(5.2$ to 11.5$)$ & $8.7(6.9$ to 10.5$)$ & $9.1(6.0$ to 12.2$)$ & $13.2(7.2$ to 10.3$)$ \\
\hline \multicolumn{5}{|l|}{ Location in US } \\
\hline Northeast & 13.4 (8.9 to 17.8 ) & $13.0(10.6$ to 15.5$)$ & 17.3 (12.5 to 22.1$)$ & 24.6 (22.5 to 26.8 ) \\
\hline Midwest & 35.5 (29.0 to 42.1$)$ & 22.4 (19.6 to 25.3$)$ & 22.2 (17.2 to 27.2 ) & 24.0 (22.0 to 26.0 ) \\
\hline South & $29.7(23.8$ to 35.6$)$ & 44.3 (41.1 to 47.5 ) & 40.4 (34.9 to 46.0 ) & $31.1(29.1$ to 33.1$)$ \\
\hline West & 21.4 (16.3 to 26.6$)$ & $20.3(17.6$ to 22.9$)$ & 20.1 (15.6 to 24.7 ) & 20.3 (18.5 to 22.0 ) \\
\hline \multicolumn{5}{|l|}{ Child in house $<15$ years } \\
\hline Yes & 45.4 (38.9 to 52.0 ) & 36.5 (33.3 to 39.7 ) & 38.6 (33.1 to 44.2 ) & 36.9 (34.7 to 39.1$)$ \\
\hline No & 54.6 (48.0 to 61.1$)$ & 63.5 (60.3 to 66.7) & $61.4(55.9$ to 67.0$)$ & $63.1(61.0$ to 65.3$)$ \\
\hline \multicolumn{5}{|c|}{ Population density (based on number of households $[\mathrm{HH}]$ ) } \\
\hline Urban $(>20000 \mathrm{HH})$ & $72.2(65.9$ to 78.5$)$ & 73.2 (70.2 to 76.2 ) & 81.5 (76.9 to 86.1$)$ & $87.5(85.8$ to 89.1$)$ \\
\hline Rural & 27.8 (21.5 to 34.1$)$ & $26.8(23.8$ to 29.8$)$ & 18.6 (14.0 to 23.2 ) & 12.5 (10.9 to 14.2 ) \\
\hline \multicolumn{5}{|l|}{ Type of dwelling } \\
\hline Attached home & $8.1(5.0$ to 11.1$)$ & 13.4 (11.3 to 15.5$)$ & 30.4 (25.2 to 35.6$)$ & $31.0(29.0$ to 33.0$)$ \\
\hline Detached home & $91.9(88.9$ to 95.9$)$ & 86.6 (84.5 to 88.7 ) & $69.6(64.4$ to 74.8$)$ & $69.0(67.1$ to 71.0$)$ \\
\hline
\end{tabular}

Based on the answers to these questions, we created four mutually exclusive categories: (1) respondents with a firearm in the household and with ready access to a loaded weapon, (2) those with a firearm in the household, but without ready access, (3) those without a firearm in the household, yet with ready access, and (4) those with neither a firearm nor ready access. Throughout this paper, the term "firearm ownership" refers to the presence of a firearm in the household, regardless of who actually owns it.

Data were weighted to generate national estimates. Weights include both a selection probability weight and a poststratification weight. Selection probability weights were the inverse of the probability of selecting a particular household type, a household member of the specified gender, and the number of telephone numbers in the household. Poststratification weights were ratio adjustments based on the March 1994 Current Population Survey number of households to the study estimates by census region and location within a metropolitan statistical area. SUDAAN software was used to generate weighted estimates for each of the four categories described above and $95 \%$ confidence intervals. ${ }^{12}$

To further examine the demographic differences between firearm ownership and access, we used logistic regression to generate adjusted odds ratios for three separate models. The outcome for the first model was firearm ownership ( $1=$ yes, $0=$ no $)$ and for the second model, it was access $(l=y e s, 0=$ no $)$. The outcome for the third model was ownership $(\mathrm{l}=$ no, $0=$ yes) among those reporting access. The same demographic variables were included in each of the three models. The main purpose of this analysis was to determine whether the variables associated with these different ownership/access categories were similar or not.

\section{RESULTS}

Of the total 5238 survey respondents, 5056 (96.5\%) provided information about both firearm ownership and their ability to retrieve and fire a loaded gun in less than 10 minutes. Of these, $1353(27.9 \%)$ reported both having a firearm and being able to fire a weapon in less than 10 minutes. An additional 313 respondents $(8.1 \%)$ reported having a firearm, but were without ready access to a loaded weapon. Another 421 respondents $(7.2 \%)$ did not own a firearm, yet reported being able to retrieve and fire one within 10 minutes. The remaining 2969 respondents $(56.8 \%)$ had neither a firearm in their home nor the ability to retrieve one quickly.

The distribution of respondent demographic characteristics within each of the four ownership/access categories are presented in table 1, whereas the distribution of these demographic characteristics across the ownership/access categories are displayed in table 2. Given our focus on whether ownership is a reasonable proxy for access, the data of primary interest in both tables are located in the second and third columns. Of respondents reporting both ownership and access, the majority were male, white, married, living in detached homes, and in urban areas (table 1). Relatively similar majority characteristics were seen for the 421 respondents who do own a firearm, yet had ready access to one.

However, differences for particular subgroups emerged upon examination of the data in table 2. For example, younger persons aged 18-34 years living in homes without firearms were more likely to report access to one than their older counterparts. Similarly, ethnic minorities without firearms in their homes $(11.7 \%$ and $12.5 \%)$ were more likely to report access compared with white, non-Hispanics $(6.2 \%)$. In contrast, those reporting both household ownership and access were 
Table 2 Distribution of respondent demographic characteristics across the different ownership/access categories; results are weighted $\%(95 \%$ confidence intervals)

\begin{tabular}{|c|c|c|c|c|c|}
\hline Characteristics & Total & $\begin{array}{l}\text { Ownership/access } \\
\text { Yes/no }\end{array}$ & $\begin{array}{l}\text { Ownership/access } \\
\text { Yes/yes }\end{array}$ & $\begin{array}{l}\text { Ownership/access } \\
\text { No/yes }\end{array}$ & $\begin{array}{l}\text { Ownership/access } \\
\text { No/no }\end{array}$ \\
\hline & 5056 & $8.1(7.1$ to 9.1$)$ & 27.9 (26.4 to 29.5$)$ & $7.2(6.4$ to 8.1$)$ & $56.8(55.1$ to 58.5$)$ \\
\hline \multicolumn{6}{|c|}{ 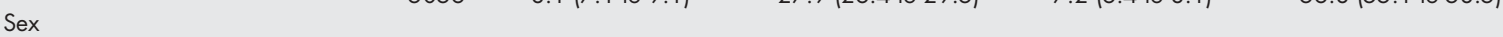 } \\
\hline Male & 2575 & 4.8 (3.8 to 5.7$)$ & $38.7(36.4$ to 41.1$)$ & $8.6(7.4$ to 9.8$)$ & $47.9(45.6$ to 50.3$)$ \\
\hline Female & 2481 & $11.2(9.5$ to 12.9$)$ & $18.0(16.0$ to 19.9$)$ & $6.0(4.9$ to 7.0$)$ & 64.9 (62.5 to 67.4$)$ \\
\hline \multicolumn{6}{|l|}{ Age group (years) } \\
\hline $18-34$ & 1869 & $6.2(4.7$ to 7.6$)$ & 28.3 (25.7 to 30.9$)$ & $9.7(8.1$ to 11.2$)$ & 55.8 (53.0 to 58.7$)$ \\
\hline $35-54$ & 1905 & $9.4(7.6$ to 11.2$)$ & $29.7(27.1$ to 32.3$)$ & $5.8(4.6$ to 6.9$)$ & $55.2(52.4$ to 58.0$)$ \\
\hline $55+$ & 1227 & $9.0(6.9$ to 11.1$)$ & $25.5(22.5$ to 28.5$)$ & $5.6(4.2$ to 7.0$)$ & 59.9 (56.5 to 63.3$)$ \\
\hline \multicolumn{6}{|l|}{ Race/ethnicity } \\
\hline White, non-Hispanic & 3647 & $9.2(8.0$ to 10.5$)$ & $31.6(29.7$ to 33.4$)$ & $6.2(5.3$ to 7.1$)$ & $53.0(51.0$ to 55.1$)$ \\
\hline Black, non-Hispanic & 664 & $4.2(2.1$ to 6.3$)$ & 15.7 (12.0 to 19.5$)$ & 11.7 (8.9 to 14.5 ) & $68.4(63.9$ to 72.9$)$ \\
\hline Other, non-Hispanic & 230 & $4.1(0.7$ to 7.4$)$ & 20.2 (13.0 to 27.4$)$ & $6.5(2.8$ to 10.2$)$ & 69.3 (61.4 to 77.2 ) \\
\hline Hispanic & 475 & $5.0(2.7$ to 7.3$)$ & 12.5 (8.8 to 16.2 ) & $12.5(9.0$ to 16.1$)$ & 69.9 (64.9 to 75.0$)$ \\
\hline \multicolumn{6}{|l|}{ Marital status } \\
\hline Married & 2623 & 9.9 (8.5 to 11.3$)$ & $32.4(30.3$ to 34.5$)$ & $6.0(5.1$ to 7.0$)$ & 51.7 (49.4 to 54.0$)$ \\
\hline Not married & 2399 & $5.4(4.1$ to 6.8$)$ & $21.2(19.0$ to 23.5$)$ & 8.9 (7.5 to 10.3$)$ & 64.5 (61.9 to 67.0$)$ \\
\hline \multicolumn{6}{|l|}{ Education } \\
\hline$\leqslant$ High school & 2106 & $8.2(6.6$ to 9.8$)$ & 27.8 (25.3 to 30.2$)$ & $8.3(6.9$ to 9.6$)$ & $55.8(53.1$ to 58.5$)$ \\
\hline$>$ High school, $\leqslant$ college & 2258 & $8.5(7.0$ to 10.0$)$ & $29.8(27.5$ to 32.2$)$ & $6.4(5.3$ to 7.5$)$ & 55.3 (52.8 to 57.9$)$ \\
\hline Postgraduate & 664 & $6.0(3.8$ to 8.3$)$ & 21.6 (17.6 to 25.7$)$ & $5.8(3.8$ to 7.8$)$ & $66.6(62.1$ to 71.1$)$ \\
\hline \multicolumn{6}{|l|}{ Location in US } \\
\hline Northeast & 813 & 5.4 (3.5 to 7.3$)$ & $18.2(14.9$ to 21.6$)$ & $6.3(4.4$ to 8.2$)$ & $70.1(66.2$ to 74.0$)$ \\
\hline Midwest & 1033 & $11.8(9.2$ to 14.4$)$ & $25.7(22.4$ to 28.9$)$ & $6.6(4.9$ to 8.2$)$ & $56.0(52.3$ to 59.7$)$ \\
\hline South & 2108 & $6.8(5.3$ to 8.3$)$ & $35.0(32.4$ to 37.6$)$ & $8.3(6.9$ to 9.6$)$ & $49.9(47.2$ to 52.6$)$ \\
\hline West & 1102 & $8.5(6.4$ to 10.7$)$ & 27.8 (24.4 to 31.2 ) & $7.2(5.4$ to 8.9$)$ & 56.5 (52.9 to 60.2 ) \\
\hline \multicolumn{6}{|l|}{ Child in house $<15$ years } \\
\hline Yes & 1911 & 9.8 (8.0 to 11.5$)$ & 27.1 (24.6 to 29.6 ) & $7.4(6.1$ to 8.7$)$ & 55.7 (53.0 to 58.4$)$ \\
\hline No & 3142 & 7.1 (5.8 to 8.3$)$ & $28.4(26.4$ to 30.4$)$ & $7.1(6.1$ to 8.2$)$ & $57.4(55.2$ to 59.6$)$ \\
\hline \multicolumn{6}{|c|}{ Population density (based on number of households [HH]) } \\
\hline Urban $(>20000 \mathrm{HH})$ & 4342 & $7.1(6.1$ to 8.2$)$ & $25.0(23.4$ to 26.6$)$ & $7.2(6.3$ to 8.1$)$ & $60.7(58.9$ to 62.5$)$ \\
\hline Rural & 714 & $12.4(9.2$ to 15.5$)$ & $41.2(36.8$ to 45.5$)$ & $7.4(5.4$ to 9.4$)$ & $39.1(34.8$ to 43.5$)$ \\
\hline \multicolumn{6}{|l|}{ Type of dwelling } \\
\hline Attached home & 1555 & $2.7(1.7$ to 3.8$)$ & $15.5(13.2$ to 17.8$)$ & $8.8(7.2$ to 10.5$)$ & $73.0(70.2$ to 75.7$)$ \\
\hline Detached home & 3460 & $9.9(8.6$ to 11.2$)$ & $31.9(30.0$ to 33.8$)$ & $6.5(5.6$ to 7.4$)$ & $51.8(49.7$ to 53.8$)$ \\
\hline
\end{tabular}

more likely to be white, non-Hispanic (31.6\%) compared with black, non-Hispanic (15.7\%) or Hispanic (12.5\%).

These differences are further highlighted by the logistic regression results (table 3). The demographic characteristics associated with ownership and access (models 1 and 2) appear very similar. This is because the majority of persons who report ownership also report access to a firearm. On the other hand, the pattern of characteristics seen in model 3 (access without ownership) are very different. Unlike the other two models, persons in this group are more likely to be female, Hispanic or black, non-Hispanic, single, and living in attached homes compared with the respective referent groups.

\section{DISCUSSION}

While the majority of respondents in our study with ready access to a loaded firearm lived in households containing firearms, a sizeable proportion did not own a firearm, yet said they would be able to retrieve a loaded firearm quickly. This analysis provides unique descriptive information about this subgroup. Our comparison of the demographic characteristics of this subgroup to those with firearms in the home revealed important differences, particularly for some populations.

These findings raise two concerns about using firearm ownership as a proxy for ready access. Although using this measure as an indicator for access yields a reasonable aggregate estimate, some respondents with ready access to a loaded firearm are likely to be missed if only firearm ownership is assessed. More importantly, using ownership may be an imperfect measure of access, particularly for certain populations at high risk for firearm related injury. Our findings indicate that racial/ethnic minorities and those living in attached homes are more likely to report ready access to loaded firearms, even though they do not live in homes containing a firearm.

These findings should be interpreted in light of several limitations. First, the response rate for the survey is lower than desirable. Although our survey household and respondent characteristics are similar to those found in the United States population, ${ }^{13}$ some selection bias may exist. We do not know how survey refusers differ from participants regarding the variables under study. Most of the survey refusals (66.3\%) occurred before any mention of the specific subject matter (for example, firearms). The refusal rate for the firearm module was low (1.8\%). Second, the prevalence of households with firearms in our survey (34\%) is lower than that reported in polls $(41 \%)$ for the same year, ${ }^{14}$ perhaps because our introductory question specifically excluded "BB and pellet guns, teargas guns, and guns that can't fire". However, it is similar to that observed in the 1994 National Health Interview Survey ${ }^{15}$ and another national telephone survey about using firearms for protection (36\%). ${ }^{16}$ Finally, no universally accepted definition of "ready access" exists, although previous research has suggested that many impulsive suicides occur within a 10 minute time window. ${ }^{17}$ The question used in this survey was modified from one previously used in a state based survey of behavioral risk factors.

Information about access to firearms is important for prevention purposes, since many interventions and policies to prevent firearm related injuries involve restricting access to firearms, either generally in a population or among specific high risk groups (children, suicidal persons) ${ }^{2-4}$ Efforts to promote the safe storage of firearms are intended to reduce immediate access to persons who are either unauthorized to use the firearm or who require adult supervision. However, to evaluate the effectiveness of these interventions and policies, 
Table 3 Adjusted odds ratios and 95\% confidence intervals for three logistic regression models

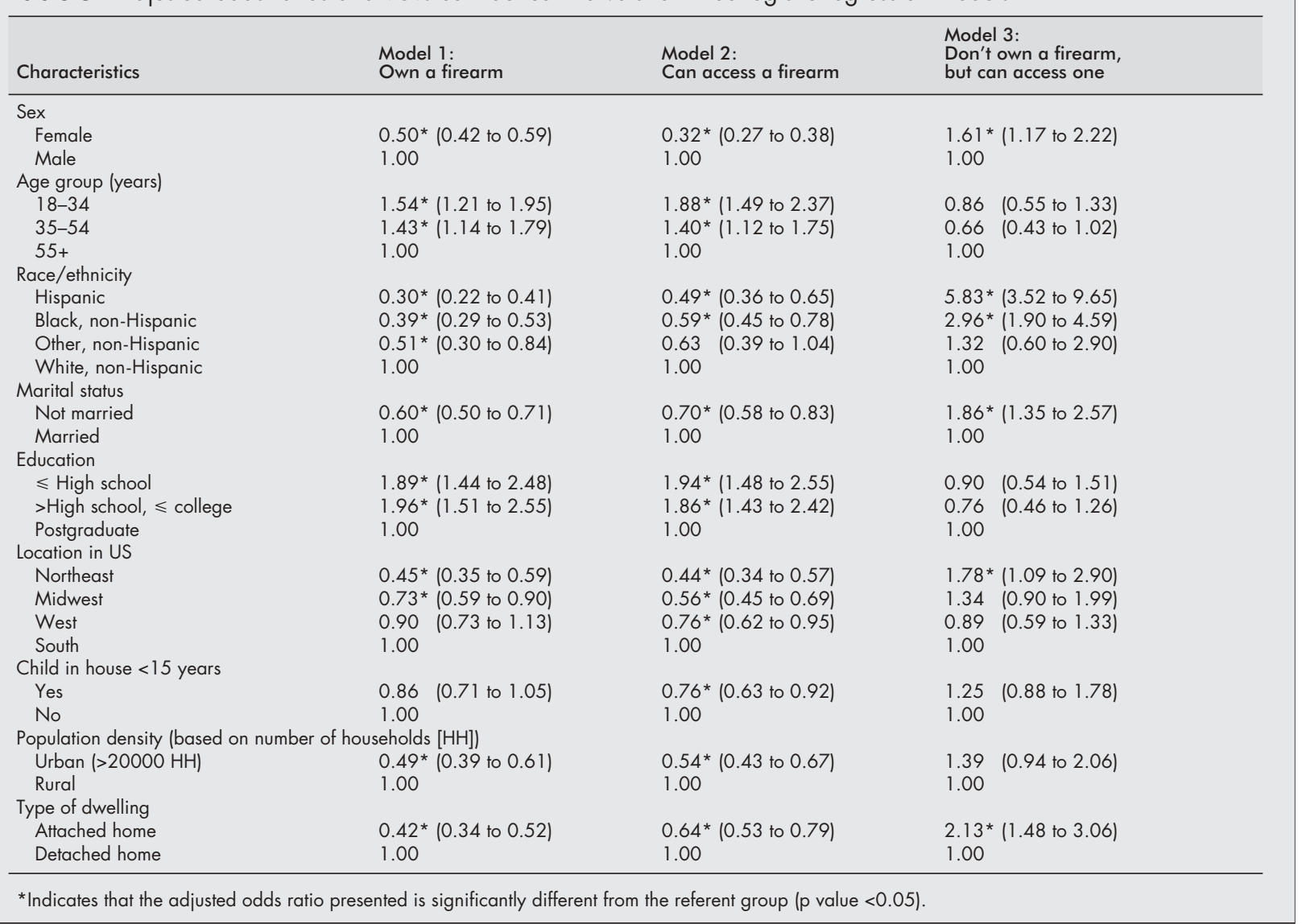

accurate measures of access are needed, regardless of the level of firearm ownership. Measuring access is also likely to remain important as new policies, such as child access protection laws, and new technologies, such as user authorized weapons (that is, "smart guns"), are introduced and implemented.

As this study has shown, firearm ownership may not be a complete indicator of ready access. We cannot assume that persons without a gun in their household are not able to access a firearm readily. Although our data do not explain why certain groups without firearms in the home are more likely to report ready access to them, it is important to note that persons without a firearm in their household, but with ready access, are among the groups identified at high risk for firearm related injury, both intentional and unintentional.

Findings from this study raise methodologic questions for further study and issues to consider when designing interventions. Caution should be exercised when using questions about firearm ownership as an indicator of access, given the differences between the two groups. Although we capture the majority of those with access to loaded firearms by asking about ownership, future studies to quantify the magnitude of access should consider including non-gun owning households to obtain the most complete estimates. Similarly, interventions to reduce unauthorized access need to take into consideration that firearms may be accessible to unauthorized members of the household as well as those outside the household. Finally, efforts to prevent firearm related injury should extend beyond individuals or households and address community level factors, since our findings suggest that respondents who do not own a gun may have access to a friend or relative's firearm who lives nearby (that is, the same apartment complex), or may be able to obtain one readily in their community.

\section{ACKNOWLEDGEMENTS}

The following are members of the Injury Control and Risk Survey (ICARIS) team: Principal Investigator: Jeffrey J Sacks, MD, MPH of CDC. Project core group: Barbara Houston, Marcie-jo Kresnow, MS, Joann M O'Neil, BA, and Suzanne M Smith, MD, MPH of CDC; James Hersey PhD, Rick Williams PhD, and Aiman Zeid, MS of Battelle; Sherry Marcy, MPH and Deborah J Zivan, BA of DataStat. Project associates: Julie Bolen, PhD, Christine M Branche, PhD, Peter Briss, MD, Terence Chorba, MD, MPH, Alex Crosby, MD, MPH, Yvette Davis, VMD, MPH, Jennifer Friday, PhD, Arlene Greenspan, DrPH, PT Thomas Matte, MD, MPH, James Mercy, PhD, Phil McClain, MS, Lloyd Potter, PhD, MPH, and Kenneth E Powell, MD, MPH of CDC.

\section{Authors' affiliations}

R M Ikeda, L L Dahlberg, M-j Kresnow, J A Mercy, National Center for Injury Prevention and Control, Centers for Disease Control and Prevention, Atlanta

J J Sacks, National Center for Chronic Disease Prevention and Health Promotion, Centers for Disease Control and Prevention, Atlanta

\section{REFERENCES}

National Center for Injury Prevention and Control

(http://www.cdc.gov/ncipc/wisqars/).

2 Conwell $Y$ Duberstein PR Connor $K$, et al. Access to firearms and risk for suicide in middle-aged and older adults. Americal Journal of Geriatric Psychology 2002;10:407-16.

3 Cummings P, Grossman DC, Rivara FP, et al. State gun safe storage laws and child mortality due to firearms. JAMA 1997;278:1084-6. 4 Webster DW, Starnes M. Reexamining the association between child access prevention gun laws and unintentional shooting deaths of children. Pediatrics 2000:106:1466-9.

5 Grossman DC, Reay DT, Baker SA. Self-inflicted and unintentional firearm injuries among children and adolescents: the source of the firearm. Arch Pediatr Adolesc Med 1999;153:875-8. 
6 Bailey JE, Kellermann AL, Somes GW, et al. Risk factors for violent death of women in the home. Arch Intern Med 1997;157:777-82.

7 Brent DA, Perper JA, Allman CJ, et al. The presence and accessibility of firearms in the homes of adolescent suicides: a case-control study. JAMA 1991;266:2989-95

8 Brent DA, Perper JA, Moritz G, et al. Firearms and adolescent suicide: a community based case-control study. Am J Dis Child 1993;147:1066-

9 Kellermann AL, Rivara FP, Rushforth NB, et al. Gun ownership as a risk factor for homicide in the home. N Engl J Med 1993;329:1084-91.

10 Kellermann AL, Rivara FP, Somes G et al. Suicide in the home in relation to gun ownership. N Engl J Med 1992;327:467-72.

11 Kleck G, Hogan M. National case-control study of homicide offending and gun ownership. Social Problems 1999;46:275-93.
12 Shah BV. SUDAAN (survey data analysis software) release 6.34. Research Triangle Institute, 1993.

13 Ikeda RM, Dahlberg LL, Sacks JJ, et al. Estimating intruder-related firearm retrievals in US households, 1994 . Violence and Victims 1997: 12:363-72

14 Maguire K, Pastore AL, eds. Sourcebook of criminal justice statistics, 1994. US Department of Justice, Bureau of Justice Statistics. Washington, DC: US Government Printing Office.

15 Schuster MA Franke TM, Bastian AM, et al. Firearm storage patterns in US homes with children. Am J Public Health 2000:90:588-94.

16 Kleck G, Gertz M. Armed resistance to crime: the prevalence and nature of self-defense with a gun. Journal of Criminal Law and Criminology 1995;86:143-86.

17 Williams C, Davidson J, Montgomery I. Impulsive suicidal behavior. J Clin Psychol 1980;36:90-4.

\section{LACUNAE}

\section{"I accidentally squashed my accountant"}

German actor who weighs $121 \mathrm{~kg}$ was jailed for 15 years for squashing his accountant to death. The $\triangle$ defendant, who claimed to have accidentally fallen on his 60 year old accountant, was cleared of Imurder but found guilty of robbery and blackmail with fatal consequences (from The Age (Melbourne), November 2002, contributed by Ian Scott).

\section{Driver protects beer, not child}

Police pulled over a Mississauga driver who treated a case of beer more carefully than his 9 year old son. Ontario provincial police (OPP) officers, who are vigorously looking for seatbelt violators as part of their provincial Fall Seatbelt Campaign, stopped the motorist on highway 401 after seeing a child jumping around in the back seat. When the investigating officer approached the car, he discovered the man and his child unbuckled, while a case of beer was fastened firmly in the passenger's seat. "It was like this guy cared more for his precious beer bottles getting smashed than he did for his son going through the wind shield", said OPP Traffic Sergeant Cam Woolley. "If we can help people like this [buckle up] by slapping them with a hefty fine, they'll be that much safer" (from Mississauga News (Ontario), contributed by Carol Runyan) 